\title{
Wildfires and politics
}

Sustainable interventions to manage wildfires are needed but require understanding the causes of such events.

E arly in August this year, in the United States, senator for California Dianne Feinstein and senator for Montana Steve Daines introduced the 'Emergency Wildfire and Public Safety Act' in response to the severe impacts of wildfires in recent years. Presented as a set of legal provisions to support adaptation of forest management to the impacts of climate change across California, Montana and the West, the legislation promises to help strengthen the resilience of fires-affected communities. Among other things, it supports the retrofitting of homes with fire-resistant materials and sets to help hospitals and police stations improve their energy efficiency in order to better cope with precautionary power cuts in the wake of fire emergencies.

Later in August, raging wildfires in California made headlines. Over a couple of days, the state was struck by an unusual lightning storm at a time of incredibly hot temperatures and windy weather. According to researchers, the combined effects of such extreme and rare weather conditions led to the eruption of multiple fires that quickly spread into various areas of California. At the time of writing this editorial, more than 7,000 fires had burnt about 1.4 million acres in the state, way above the wildfires impacts registered by the same time last year. Worryingly enough, it appears that the fires this year are burning areas that do not typically experience wildfires. The multiple little fires provoked by the lightning happened in locations too remote for firefighters to get to quickly, but at the same time quite close to where people live. Hence the impacts have been much more severe, putting the lives of many residents and rescue teams at risk. Even though untying weather and climate remains challenging, experts warn that climate change is very likely to play a part in these events.

As things stand there is no doubt: California and other fire-prone regions, especially those densely populated, do need more protection and greater resilience to wildfires. Hence, the 'Emergency Wildfire and Public Safety Act' could represent a critical piece of legislation. However, since its introduction, the bill has faced push backs by environmental groups. The legislation, beyond improving preparedness of communities to wildfire emergencies, would facilitate the creation of a market for wood biomass as a mechanism to limit the spread

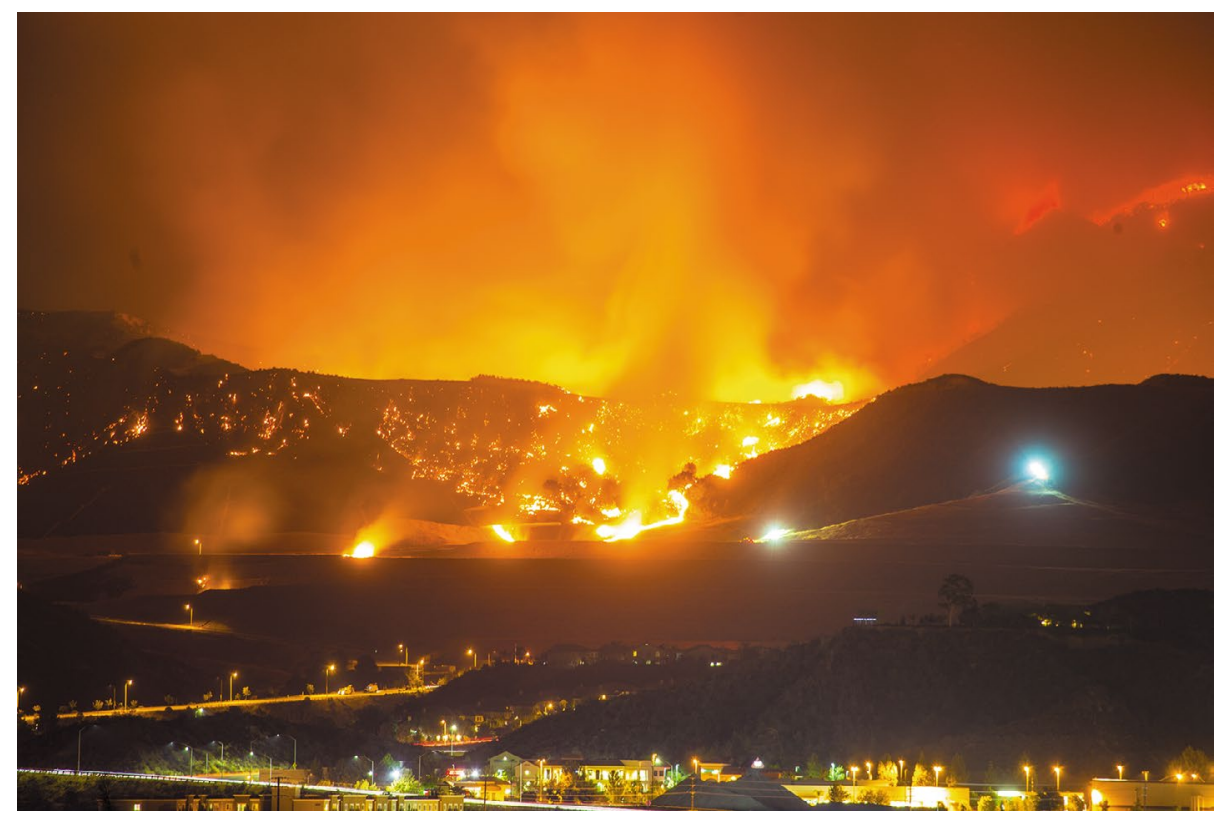

Credit: FrozenShutter / E+ / Getty

of wildfires. It seems like the bill would give the US Forest Service - the federal agency under the US Department of Agriculture currently managing 193 million acres of land - the ability to implement substantial land-based projects with limited scrutiny. For example, for logging in areas surrounding roads or transmission lines that qualify for a 3,000-acre unconditional exclusion under the bill, only limited environmental reviews would be required and there would be no obligation to consider public input on the project. Besides, environmental groups are worried that not all logging would reduce wildfires risks to communities, beyond benefiting the timber industry. And ultimately, uncontrolled logging could have impacts on ecosystems and wildlife species.

This is yet another example of how laws designed to protect communities by favouring unrestrained economic activities can impact environmental protection efforts. We need to admit that the people-nature interface is difficult to manage, and in certain contexts does pose a trade-off to policy makers. In the end, a wood biomass market means jobs, which are particularly needed in deprived communities. But research providing better understanding of the complexities of humanenvironmental connections can inform policy interventions and should ultimately guide politicians. This is the only way for policy makers to be able to learn lessons from any given intervention and improve efforts going forward. That is where failure can no longer be justified. Ignoring human-environmental connections or subjugating them to the market logic without understanding the consequences doesn't necessarily guarantee human well-being over time.

Going back to the wildfires catastrophe, experts are getting reliable predictions about where and when, across the globe, they would start, and when they would peak. Based on their analyses, it's hard to believe that managing logging will address the problem effectively. We only need to look elsewhere to realize even more clearly the role of climate change in these disasters - the recent fires in Siberia are a striking case. Overall, there is little doubt that we should expect wildfires to get worse over time. Rather than considering clearing floors in order to prevent and better cope with wildfires, affected regions should perhaps look at viable environmentally oriented interventions that create long-term opportunities for communities to stay safe and thrive.

Published online: 14 September 2020 https://doi.org/10.1038/s41893-020-00613-2 